
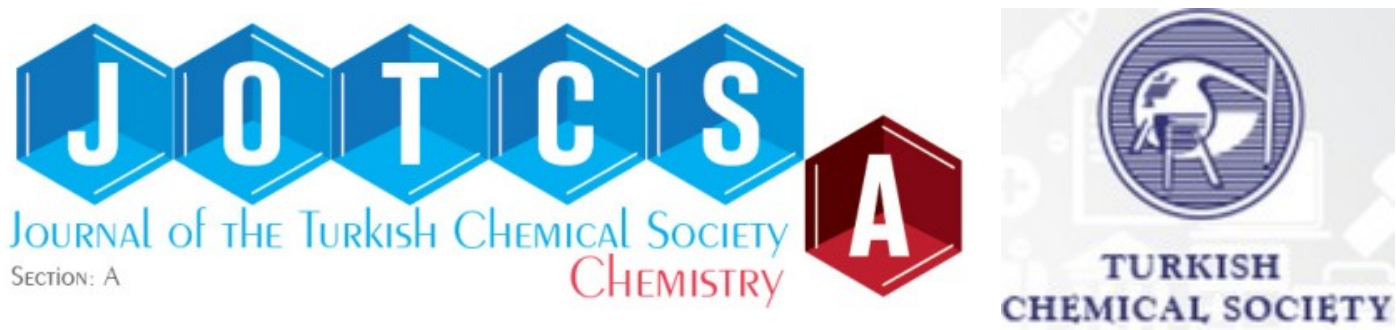

\title{
Improved Photocatalytic Degradation of Methyl Orange Dye in UV Light Irradiation by $\mathrm{K}_{2} \mathrm{Ti}_{6} \mathrm{O}_{13}$ Nanorods
}

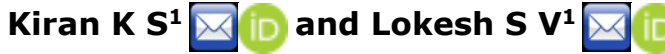 \\ ${ }^{1}$ Department of Nanotechnology, Visvesvaraya Technological University, Center for PG Studies-Bangalore \\ Region, Muddenahalli, Chikkaballapura (D)-562101, Karnataka, India.
}

\begin{abstract}
The $\mathrm{K}_{2} \mathrm{Ti}_{6} \mathrm{O}_{13}$ nanorods (KTNRs) were synthesized by Molten Salt Solution method (MSS) using $\mathrm{TiO}_{2}$ nanoparticles and potassium chloride as precursors. As synthesized KTNRs was characterized by powder X-ray diffraction to know the crystallinity, scanning electron microscopy confirms the rod type morphology with diameter 10 to $12 \mathrm{~nm}$ with length up to $80 \mathrm{~nm}$, functional groups were studied with FT-IR spectroscopy, optical property of KTNRs showed the bandgap energy $\mathrm{Eg}=3.41$ eV by UV-Vis spectrophotometry. The synthesized KTNRs was used as photocatalyst for degradation of the methyl orange dye under UV light illumination. The degradation of methyl orange dye followed the pseudo first order rate law. The kinetics and mechanism of MO dye degradation dye was studied for different photocatalyst dosage 5, 10 and $15 \mathrm{mg}$ of KTNRs, maximum for rate constant is found for $10 \mathrm{mg}$ of photocatalyst.
\end{abstract}

Keywords: Photocatalyst, Potassium Titanate nanorods, methyl orange degradation.

Submitted: July 09, 2020. Accepted: June 14, 2021.

Cite this: Kiran K, Lokesh S. Improved Photocatalytic Degradation of Methyl Orange Dye in UV Light Irradiation by K2Ti6013 Nanorods. JOTCSA. 2021;8(3):723-30.

DOI: https://doi.org/10.18596/jotcsa.766952.

*Corresponding author. E-mail: lokeshsampangi@gmail.com.

\section{INTRODUCTION}

The purification of water contaminated by cyanide is refined by titanium dioxide $\left(\mathrm{TiO}_{2}\right)$ by photocatalytic method (1) for the first time. After that the research community has investigated many nanocomposite materials with different nanostructured materials were used to find the solutions for environmental pollution problem. These nanocomposites were more attractive for environmental issues because of their properties like non-toxic, photo-stable, low cost, and insoluble in water.

Similarly, the nanocomposites consisting of onedimensional (1 D) nanostructures like nanowire, nanotubes, nanobelts, and nanorods have also engrossed the extraordinary interests due to their size dependent optical, magnetic, chemical, electronic, mechanical, and thermal properties and their promising applications in nanodevices (2-8). Even though there are large number of nanomaterials, titanium dioxide-related materials and their one-dimensional nano structured materials because of large specific surfaces and there by improving promising applications in decontamination, purification and decomposition of environmental pollutants photocatalytically (9-12).

Beside the high photocatalytic activity, potassium titanate has the distinctive crystal structure made up of layered titanium oxide layers and inter layer cations, which exhibits the brilliant ion exchange and intercalation ability. The general formula of potassium titanates consists of $\mathrm{K}_{2} \mathrm{Ti}_{n} \mathrm{O}_{2 n+1}$. Numerous methods have been developed to synthesize one-dimensional potassium titanates' nanostructures (13) with flux method (14-17). Alkali metal titanates such as $\mathrm{K}_{2} \mathrm{Ti}_{4} \mathrm{O}_{9}$ and $\mathrm{K}_{2} \mathrm{Ti}_{6} \mathrm{O}_{13}$ have great mechanical property by incorporating 
metals and plastics $(18,19)$. Many researchers follow the hydrothermal method (20-22) for synthesizing the $1-\mathrm{D} \mathrm{K}_{2} \mathrm{Ti}_{6} \mathrm{O}_{13}$ nanostructures. In this work, we have reported the synthesis of $\mathrm{K}_{2} \mathrm{Ti}_{6} \mathrm{O}_{13}$ nanorods by molten salt solution method and their potential application as photocatalyst in degrading the methyl orange dye in UV light irradiation are investigated.

\section{MATERIALS AND METHODS}

\section{Materials}

Potassium chloride (99\%) was purchased from SD Fne Chemicals, titanium (IV) isopropoxide (97\%) and methyl orange were procured from Sigma Aldrich The chemicals procured are of analytical grade and used without any further purification. Milli Q, deionized (DI) water is used throughout the experiment for preparing the solutions.

\section{Synthesis of $\mathrm{TiO}_{2}$ nanoparticles}

Initially, titanium(IV) isopropoxide of $2 \mathrm{~mL}$ volume was added to $25 \mathrm{~mL}$ of DI water and continuously stirred using magnetic stirrer at $400 \mathrm{rpm}$ for 30 minutes at room temperature; the resultant solution was further transferred to a silica crucible and heated at $150{ }^{\circ} \mathrm{C}$ using electric bunsen burner leading to the formation of $\mathrm{TiO}_{2}$ nanoparticles as titanium(IV) isopropoxide reacts with water, leaving other components to evaporate. The resultant powder was dried at $120^{\circ} \mathrm{C}$ for $2 \mathrm{~h}$ and then fine ground for 5 minutes in an agate mortar (23).
$\begin{array}{ll}\mathrm{Ti}\left(\mathrm{OCH}\left(\mathrm{CH}_{3}\right)_{2}\right)_{4}(\mathrm{~A})+\underset{\left(\mathrm{CH}_{3}\right)_{2} \mathrm{CHOH}(\mathrm{C})}{2 \mathrm{H}_{2} \mathrm{O} \rightarrow} & \mathrm{TiO}_{2}(\mathrm{~B})+4 \\ (\mathrm{Eq} .1) & \end{array}$

(A) titanium (IV) isopropoxide

(B) titanium dioxide

(C) Iso propyl alcohol

\section{Synthesis of $\mathrm{K}_{2} \mathrm{Ti}_{6} \mathrm{O}_{13}$ nanorods}

The potassium titanate nanorods are synthesized by using molten salt solution method. $0.05 \mathrm{~g}$ of titanium dioxide nanoparticles and $7.5 \mathrm{~g}$ of potassium chloride were thoroughly mixed and ground consistently in an agate mortar for $0.5 \mathrm{~h}$. Then an alumina crucible is obtained and the mixture is transferred to it and annealed at $850{ }^{\circ} \mathrm{C}$ for $3 \mathrm{~h}$ in the furnace. At this higher temperature, the reaction mixture would be in molten state. The alumina crucible is allowed to cool naturally to reach room temperature and in this cooling step crystallinity of the $\mathrm{K}_{2} \mathrm{Ti}_{6} \mathrm{O}_{13}$ would take place in the presence of molten potassium chloride. The synthesized product was collected, washed many times to remove the unreacted potassium chloride with DI, and dried at $80^{\circ} \mathrm{C}$ overnight in hot air oven.

$$
4 \mathrm{KCl}(\mathrm{A})+13 \mathrm{TiO}_{2}(\mathrm{~B}) \rightarrow 2 \mathrm{~K}_{2} \mathrm{Ti}_{6} \mathrm{O}_{13}+\mathrm{TiCl}_{4}(\mathrm{C})
$$
(A) Potassium chloride
(B) Titanium dioxide
(C) Titanium(IV) chloride

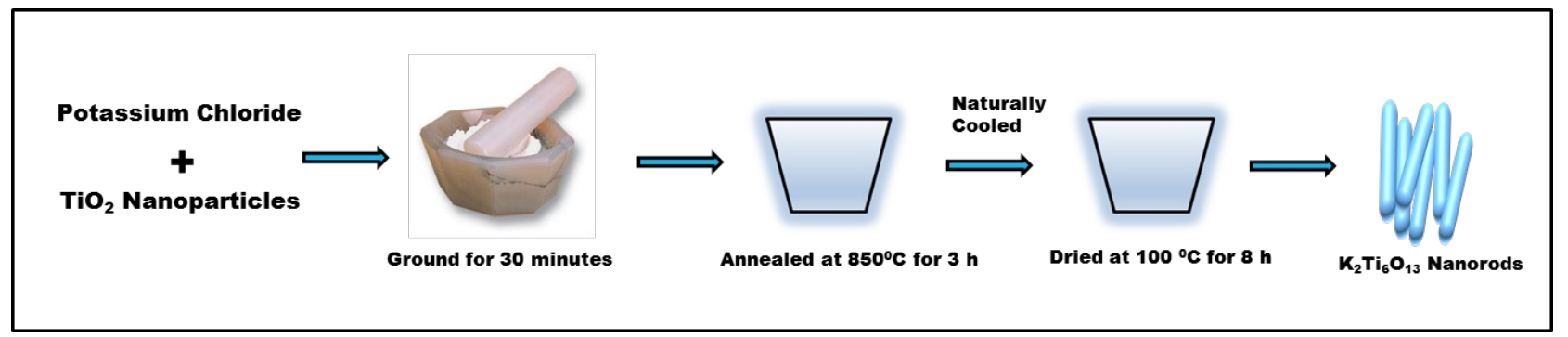

Figure 1: Schematic representation of Synthesis of $\mathrm{K}_{2} \mathrm{Ti}_{6} \mathrm{O}_{13}$ nanorods.

\section{Characterization Techniques}

The synthesized $\mathrm{K}_{2} \mathrm{Ti}_{6} \mathrm{O}_{13}$ nanorods were characterized by various advanced analytical spectroscopic methods such as the powder X-ray diffraction (PXRD) study were performed using Rigaku Ultima IV diffractometer using $\mathrm{Cu} \mathrm{Ka}$ radiation with $\lambda=0.15406 \mathrm{~nm}$ in the range $10^{\circ}$ $70^{\circ}$ for phase confirmation. In transmittance mode UV-Visible absorption spectrophotometry was performed by a Perkin Elmer Lambda 750 in the range of 200-800 $\mathrm{nm}$. The Optical Bandgap Eg was measured by plotting (ahu) ${ }^{2}$ versus photon energy Ev. Morphology of the synthesized $\mathrm{K}_{2} \mathrm{Ti}_{6} \mathrm{O}_{13}$ nanorods were confirmed by Scanning Electron Microscopy Vega 3 Tescan. Functional group study was performed by Fourier Transform Infrared spectroscopy with a Perkin Elmer Spectrum Two.

\section{RESULTS AND DISCUSSION}

\section{Powder XRD analysis}

The powder $X$-ray diffraction patterns of as synthesized $\mathrm{K}_{2} \mathrm{Ti}_{6} \mathrm{O}_{13}$ nanorods was as shown in Figure 2. The XRD patterns were completely matched with the standard literature JCPDS card number 74-0275 with no additional impurities. The diffraction patterns indexed as pure monoclinic system with $\mathrm{C} 2 / \mathrm{m}$ phase (24) of $\mathrm{K}_{2} \mathrm{Ti}_{6} \mathrm{O}_{13}$ with $a=15.58 \AA, \quad b=3.820 \AA, c=9.112 \AA$, and $\beta=99.764^{\circ}$. The intense diffraction peak corresponding to $\mathrm{hkl}$ values (200) was for $2 \theta$, 
11.34 degrees. The crystallite size of the as synthesized product was calculated using Scherrer's equation: The size of the nanoparticles was calculated by using Scherrer's formula $D=0.9 \lambda / \beta \cos \theta$ where $D$ is the crystalline size, $\lambda$ is wavelength of $X$-rays, $\beta$ is full width half maximum of the diffraction peak and $\theta$ is the Bragg's diffraction angle of the diffraction peaks. The average particle size was found to be and average crystallite found to be $52 \mathrm{~nm}$.

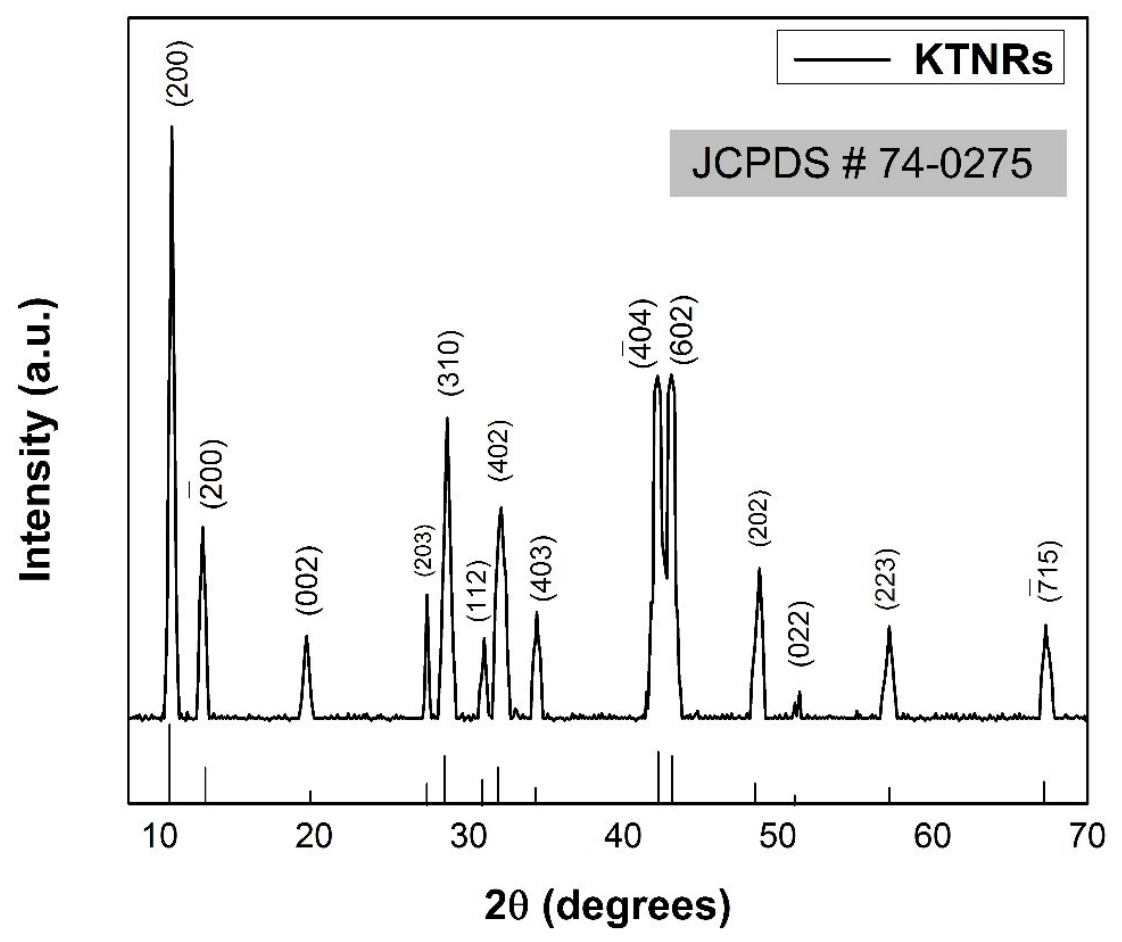

Figure 2: XRD patterns of potassium titanate nanorods.

Scanning Electron Microscopic analysis The Scanning electron microscopic (SEM) images were used to analyze the morphology of the assynthesized potassium titanate nanorods. Figure 4 a) and b) show the synthesized potassium titanate nanorods at $1.0 \mu \mathrm{m}$ and $10 \mu \mathrm{m}$, respectively. Morphology of the samples were found to be rodshaped. 


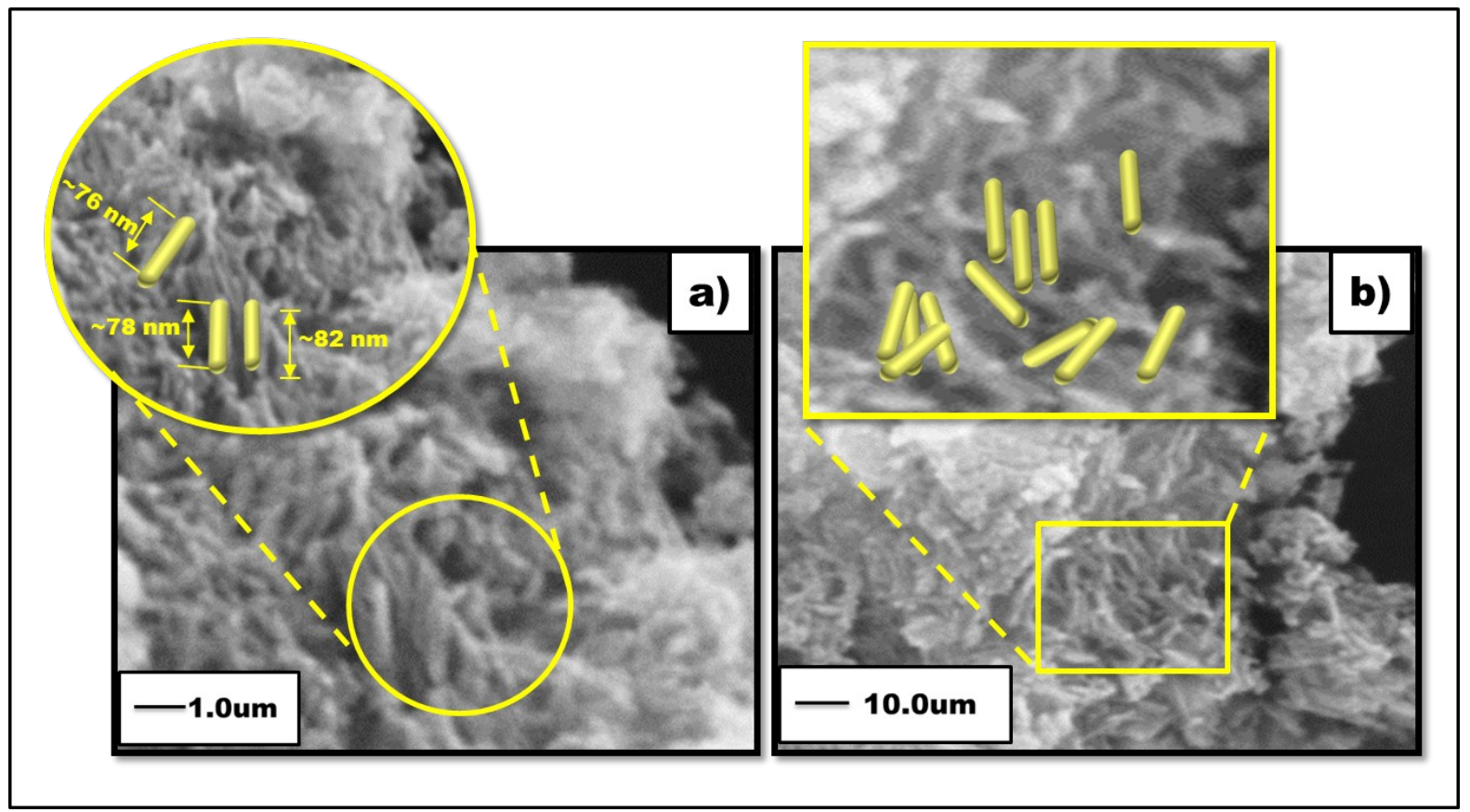

EDAX analysis

Figure 3: SEM images of KTNRs at magnifications a) $1.0 \mu \mathrm{m}$ b) $10 \mu \mathrm{m}$.

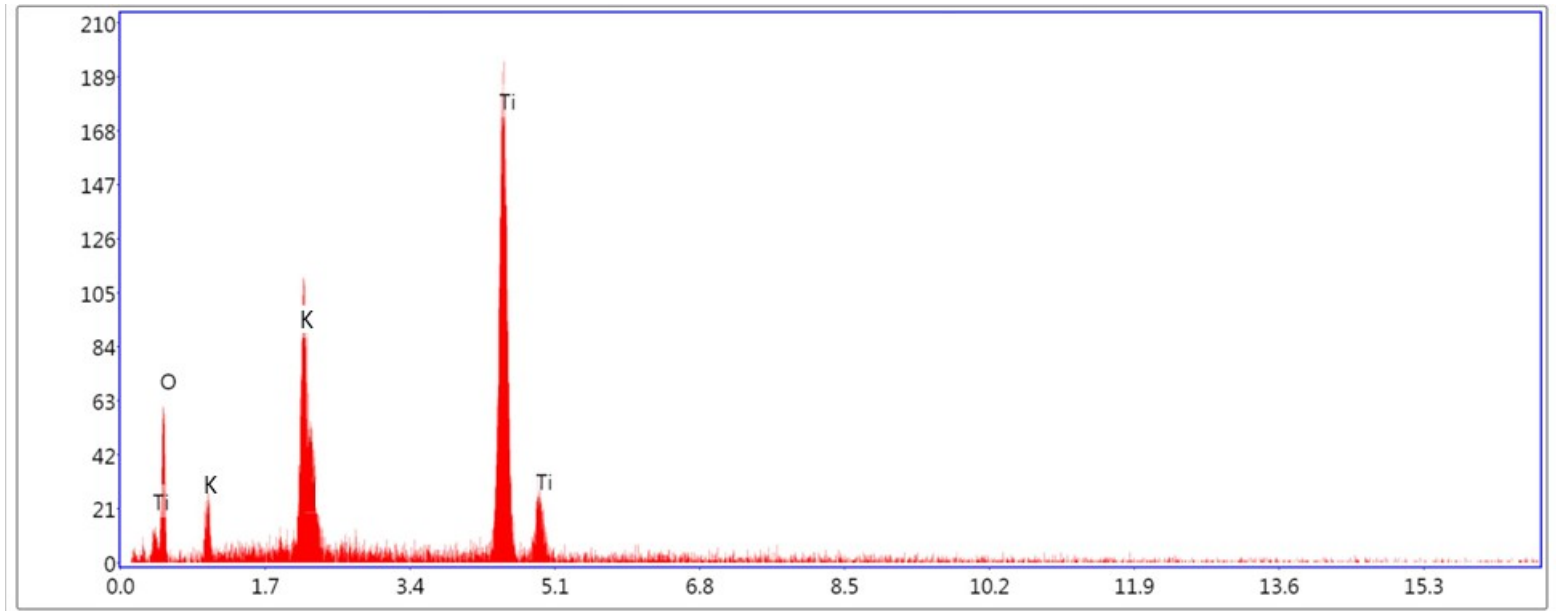

Lsec: $25.8 \quad 29$ Cnts $1.060 \mathrm{keV} \quad$ Det: Octane Pro Det

Figure 4: EDX elemental analysis spectra of $\mathrm{K}_{2} \mathrm{Ti}_{6} \mathrm{O}_{13}$ nanorods.

In order to determine the composition of the as synthesized products examined by Energy Dispersive X-ray spectroscopy (EDAX). Figure 4 shows the elemental analysis data.

Table 1: Elemental data of $\mathrm{K}_{2} \mathrm{Ti}_{6} \mathrm{O}_{13}$ nanorods.

\begin{tabular}{ccc}
\hline Element & Weight \% & Atomic \% \\
\hline $\mathrm{O}$ & 24.28 & 42.73 \\
$\mathrm{~K}$ & 9.53 & 13.81 \\
$\mathrm{Ti}$ & 66.19 & 43.46 \\
\hline
\end{tabular}

The as-synthesized product from molten salt synthesis method are pure and free from impurities and the ratio was found to be $1: 3$ for potassium to titanium atomic ratio.

\section{UV-Visible spectrophotometry}

The UV-Vis absorption spectra and Bandgap energy plot was shown in Figure 5 (a) \& (b) Bandgap energy Eg plot. Absorption spectra for potassium titanate nanorods was $\lambda_{\max }=325 \mathrm{~nm}$ (25). Because there is a transformation in the structure from spherical particle type to rod type. This creates a unique electronic property. Bandgap energy $\mathrm{Eg}$ is $3.41 \mathrm{eV}$ for as-synthesized potassium titanate nanorods were calculated from the plot, $(\mathrm{ahu})^{2} \mathrm{v} / \mathrm{s}$ photon energy $\mathrm{eV}$, which is very close to literature value (26). 

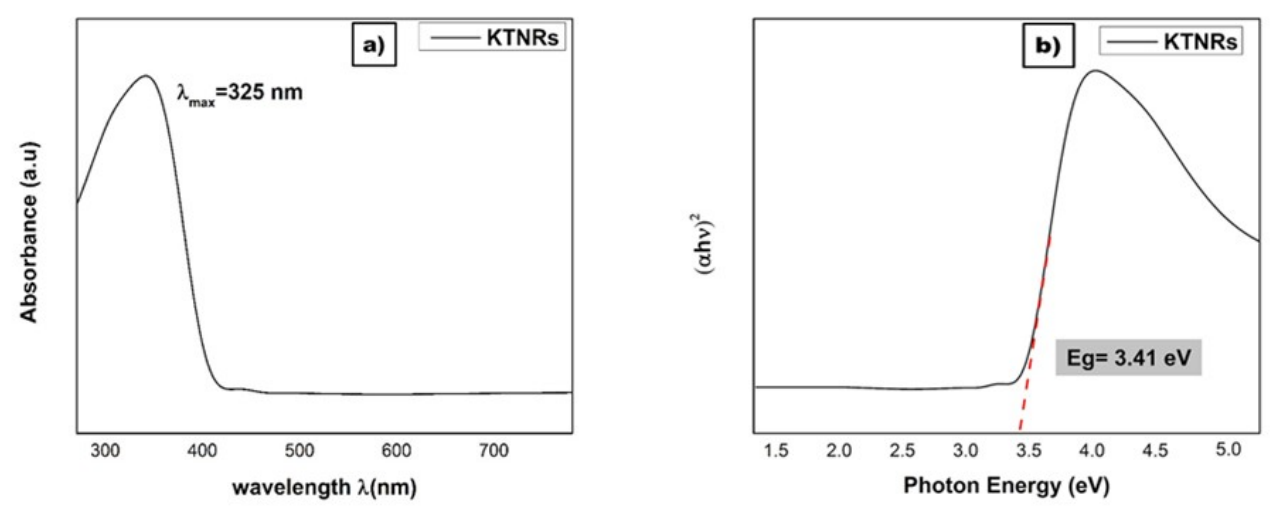

Figure 5 a) UV-Visible absorption plot absorbance (a.u.) v/s wavelength $\lambda(\mathrm{nm}$ ) of KTNRs b). Bandgap energy Eg of KTNRs plot, (ahu) $)^{2} \mathrm{v} / \mathrm{s}$ photon energy $\mathrm{eV}$.

\section{FT IR analysis}

FTIR for potassium titanate nanorods was as shown in Figure 6. The two prominent absorptions were observed at $3358.3 \mathrm{~cm}^{-1}$ and $1640.8 \mathrm{~cm}^{-1}$ which are designated to $\mathrm{O}-\mathrm{H}$ bending vibrations and $\mathrm{H}-\mathrm{O}-\mathrm{H}$ bending vibrations of the adsorbed water molecules. Ti-O bending vibrations were observed at $550 \mathrm{~cm}^{-1}$ At $723.7 \mathrm{~cm}^{-1}$ is assigned to the vibration of $\mathrm{Ti}-\mathrm{O}-\mathrm{Ti}$ bond in the lattice (27).

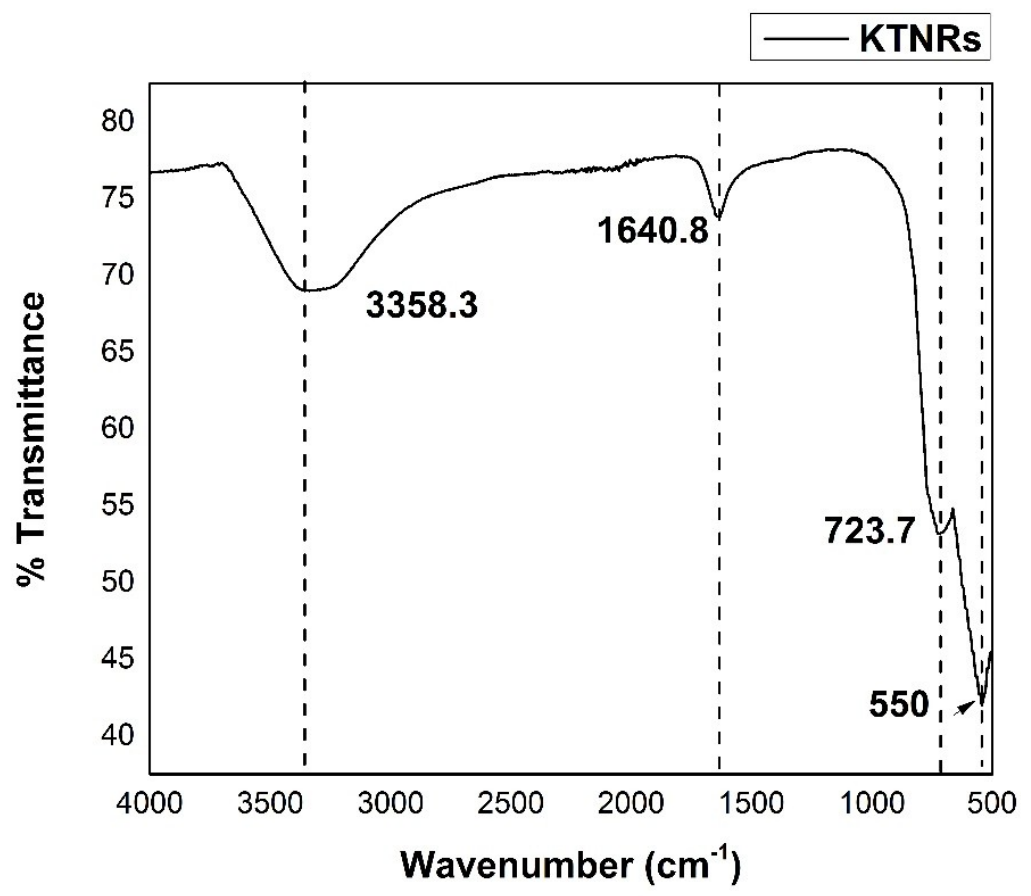

Figure 6: FTIR spectra of KTNRs.

\section{Photocatalytic degradation of methyl orange}

\section{dye}

Under UV light illumination, the degradation of $\mathrm{MO}$ (4-[[(4-dimethylamino)phenyl]-

azo]benzenesulfonic acid sodium salt) by the photocatalyst was analyzed by using an absorption-based on UV-Vis spectroscopic technique. Photocatalytic tests were carried out in a beaker made up of quartz $(150 \mathrm{~mL})$ under stirring at room temperature, being filled with an aqueous suspension ( $100 \mathrm{~mL}$ ) containing $10 \mathrm{ppm}$ of $\mathrm{MO}$ dye and catalyst $(0.10 \mathrm{~g} / \mathrm{L})$. A $300 \mathrm{~W}$ high pressure mercury lamp was positioned at $10 \mathrm{~cm}$ away from the quartz beaker, suspension was bubbled continuously with air.

Prior to irradiation, the solution mixture was ultrasonicated for $15 \mathrm{~min}$, then stirred for $0.5 \mathrm{~h}$ in dark condition to achieve the adsorption/desorption equilibrium. The 
concentration of MO after equilibrium was analyzed by recording the absorption band maximum ( $\lambda_{\max }$ $464 \mathrm{~nm}$ ) in the absorption spectra and taken as the initial concentration $\left(C_{0}\right)$. During the photocatalysis, the suspension was extracted at an interval of $30 \mathrm{~min}$, concentration $(\mathrm{C}),\left(\mathrm{C} / \mathrm{C}_{0}\right)$ of $\mathrm{MO}$ during the photo degradation were proportional to the normalized maximum absorbance and derived from the changes in the dye's absorption profile at a given time interval. For comparison, $\mathrm{K}_{2} \mathrm{Ti}_{6} \mathrm{O}_{13}$ nanorods were characterized under the same conditions.

The degradation efficiency $(n)$ was measured by using following formula $n=(1-C) /$ Co where, Co is the initial concentration before irradiation with light and $\mathrm{C}$ is the concentration of dye after irradiation. The degradation efficiency of $\mathrm{MO}$ was analyzed using UV-Vis spectrometer. Peaks were observed to be at $464 \mathrm{~nm}$ and were assigned as the absorption of the $\Pi$-system (28), which was indicative of the degradation of methyl orange dye shown in Figure 7 a) and Percentage of degradation in $7 \mathrm{~b}$ ). In Figure $7 \mathrm{c}$ ) Degradation of MO can be seen with time. Initially the absorbance was 0.9412 and gradually decreased with time and irradiation of UV-Vis light to 0.0252 at $240 \mathrm{~min}$. The rate constant was found to be $0.000314 \mathrm{~min}^{-1}$ for $10 \mathrm{mg}$ of photocatalytic dosage.

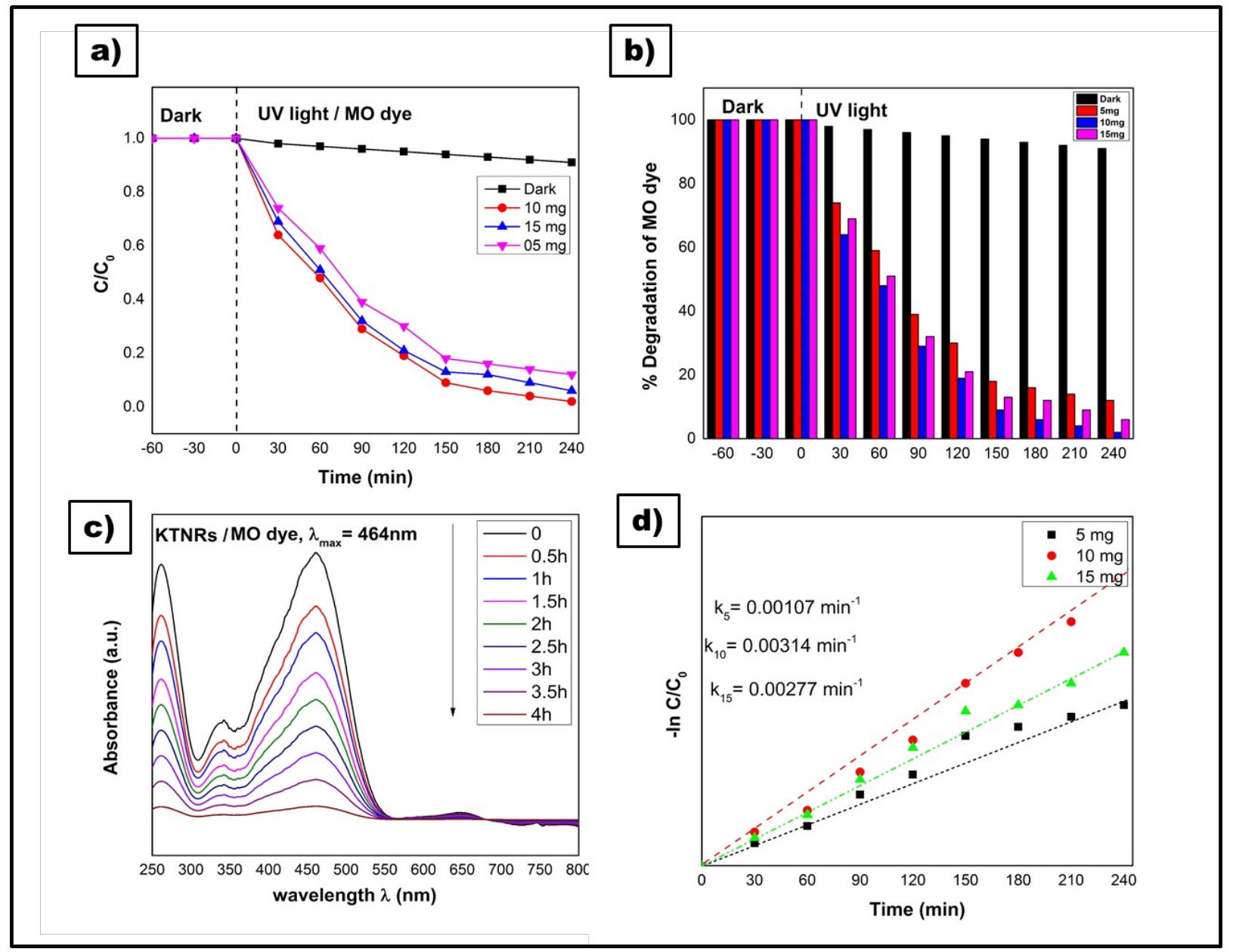

Figure 7: Photocatalytic degradation of $\mathrm{K}_{2} \mathrm{Ti}_{6} \mathrm{O}_{13}$ nanorods of different photocatalyst loading a) Concentration $\mathrm{C} / \mathrm{C}_{0} \mathrm{v} / \mathrm{s}$ Irradiation Time (min) b) Percentage degradation $\mathrm{v} / \mathrm{s}$ Irradiation Time (min) c) Absorbance (a. u.) v/s wavelength $\lambda(\mathrm{nm})$ of $10 \mathrm{mg}$ KTNRs d) rate constant plot: $-\ln \mathrm{C} / \mathrm{C}_{0} \mathrm{v} / \mathrm{s}$ Time (min)

The same photocatalytic degradation reaction is repeated keeping all the conditions same but changing the weight of photocatalyst. The effect of photocatalytic dosage was varied from $5 \mathrm{mg}$ and $15 \mathrm{mg}$. The rate constant was found more for 10 mg photocatalyst than $5 \mathrm{mg}$ and $15 \mathrm{mg}$ due to the availability of number of active sites on the surface of the sample increases with increasing the amount of photocatalyst. In this way, the number of superoxide and hydroxyl radicals also increases. However, the rate of reaction decreases due to the covering the active sites of the suspension for photocatalyst. There by the light radiation will not fall on the active sites to proceed the reaction. 
Table 2: Photocatalytic dosage and rate constant of the reaction for KTNRs.

\begin{tabular}{|c|c|c|}
\hline \multirow{4}{*}{$\begin{array}{l}\text { For photocatalytic } \\
\text { degradation of MO dye by } \\
\text { KTNRs with } 10 \mathrm{ppm} \\
\text { concentration }\end{array}$} & Photocatalytic dosage & Rate constant, min $^{-1}$ \\
\hline & $5 \mathrm{mg}$ & 0.000107 \\
\hline & $10 \mathrm{mg}$ & 0.000314 \\
\hline & $15 \mathrm{mg}$ & 0.000277 \\
\hline
\end{tabular}

The $\mathrm{K}_{2} \mathrm{Ti}_{6} \mathrm{O}_{13}$ nanorods has a structure as that of semiconductors, on irradiating to UV light generates the electron hole pairs after attaining the equilibrium/desorption in dark condition. The photo generated electron hole pairs follows the reaction and gradually degrade the $\mathrm{MO}$ dye to $\mathrm{CO}_{2}$ and $\mathrm{H}_{2} \mathrm{O}$. The plausible reaction mechanism $(29,30)$ as follows:

$$
\begin{aligned}
& \mathrm{K}_{2} \mathrm{Ti}_{6} \mathrm{O}_{13}+\mathrm{hu} \rightarrow \mathrm{K}_{2} \mathrm{Ti}_{6} \mathrm{O}_{13}\left(\mathrm{e}^{-}{ }_{(\mathrm{CB})}+\mathrm{h}^{+}{ }_{(\mathrm{VB}))}(\mathrm{Eq} \cdot 3)\right. \\
& \mathrm{O}_{2}+\mathrm{e}^{-} \rightarrow \mathrm{O}^{-} \\
& \mathrm{H}_{2} \mathrm{O}+\mathrm{h}^{+} \quad \rightarrow-\mathrm{OH}+\mathrm{H}^{+} \\
& -\mathrm{OH}+\mathrm{h}^{+} \rightarrow \cdot \mathrm{OH} \\
& \cdot \mathrm{O}_{2}+\mathrm{H}^{+} \rightarrow{ }^{-} \mathrm{HO}_{2} \\
& \mathrm{MO}+\mathrm{hu} \rightarrow \mathrm{MO} \cdot \\
& \mathrm{MO}^{-}+\mathrm{K}_{2} \mathrm{Ti}_{6} \mathrm{O}_{13} \rightarrow \mathrm{MO}+\mathrm{K}_{2} \mathrm{Ti}_{6} \mathrm{O}_{13} \mathrm{e}^{-} \text {(CB) (Eq.9) } \\
& \mathrm{K}_{2} \mathrm{Ti}_{6} \mathrm{O}_{13} \mathrm{e}^{-}{ }_{(\mathrm{CB})}+\mathrm{O}_{2} \quad \mathrm{~K}_{2} \mathrm{Ti}_{6} \mathrm{O}_{13}+\mathrm{O}_{2}^{-} \text {(Eq.10) } \\
& \mathrm{K}_{2} \mathrm{Ti}_{6} \mathrm{O}_{13} \mathrm{e}^{-}{ }_{(\mathrm{CB})}+{ }^{-} \mathrm{O}_{2}^{-}+2 \mathrm{H}^{+} \rightarrow \mathrm{K}_{2} \mathrm{Ti}_{6} \mathrm{O}_{13}+\mathrm{H}_{2} \mathrm{O}_{2} \\
& \text { (Eq.11) } \\
& \mathrm{K}_{2} \mathrm{Ti}_{6} \mathrm{O}_{13} \mathrm{e}^{-}{ }_{(\mathrm{CB})}+\mathrm{H}_{2} \mathrm{O}_{2} \rightarrow \mathrm{K}_{2} \mathrm{Ti}_{6} \mathrm{O}_{13}+\cdot \mathrm{OH}+{ }^{-} \mathrm{OH} \\
& \text { (Eq.12) }
\end{aligned}
$$

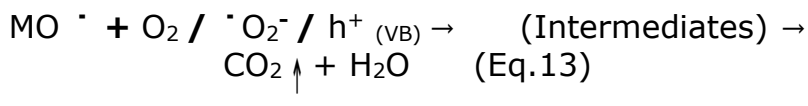

The degraded products are environmentally friendly. Hence the $\mathrm{K}_{2} \mathrm{Ti}_{6} \mathrm{O}_{13}$ nanorods can be used as promising photocatalysts for the degradation of methyl orange dye.

\section{CONCLUSIONS}

The potassium titanate nanorods were efficiently synthesized by molten salt solution method. The as synthesized $\mathrm{K}_{2} \mathrm{Ti}_{6} \mathrm{O}_{13}$ nanorods were in pure monoclinic phase with rod-like structure with average $10^{-12} \mathrm{~nm}$ diameter and length up to 80 $\mathrm{nm}$. The $\mathrm{K}_{2} \mathrm{Ti}_{6} \mathrm{O}_{13}$ nanorods showed higher photocatalytic activity of azo dye methyl orange under UV light irradiation. Hence it exhibited as a prominent photcatalyst. Three different dosage such as 5, 10 and $15 \mathrm{mg}$ was examined for photocatalytic activity, rate constant was maximum for $10 \mathrm{mg}$, even though as the size decreases the active site increases, but the rate of reaction decreases due to the blocking of the active sites of the suspension for photocatalyst.

\section{ACKNOWLEDGEMENTS}

Authors acknowledge the financial support from DST-Science and Engineering Research Board, Government of India, File no. SB/EMEQ-171/2014.

\section{REFERENCES}

1. Frank SN, Bard AJ. Heterogeneous photocatalytic oxidation of cyanide and sulfite in aqueous solutions at semiconductor powders. J Phys Chem. 1977;81(15):1484-8. DOI: https://doi.org/10.1021/j100530a011.

2. Ge M, Cao C, Huang J, Li S, Chen Z, Zhang K-Q, et al. A review of one-dimensional TiO 2 nanostructured materials for environmental and energy applications. J Mater Chem A. 2016;4(18):6772-801. DOI: https://doi.org/10.1039/C5TA09323F.

3. Lieber CM. One-dimensional nanostructures: Chemistry, physics \& applications. Solid State Communications. 1998;107(11):607-16. DOI: https://doi.org/10.1016/S0038-1098(98)00209-9.

4. Xie JL, Guo CX, Li CM. Construction of one-dimensional nanostructures on graphene for efficient energy conversion and storage. Energy Environ Sci. 2014 $30 ; 7(8): 2559$.

https://doi.org/10.1039/C4EE00531G.

5. Cho C-P, Perng T-P. One-Dimensional Organic and Organometallic Nanostructured Materials. j nanosci nanotechnol. 2008;8(1):69-87. DOI: https://doi.org/10.1166/jnn.2008.N14.

6. Nowak DJ, Hirabayashi S, Bodine A, Greenfield E. Tree and forest effects on air quality and human health in the United States. Environmental Pollution. 2014;193:11929. DOI: https://doi.org/10.1016/j.envpol.2014.05.028.

7. Xu Y, Zhang B. Recent advances in porous Pt-based nanostructures: synthesis and electrochemical applications. Chem Soc Rev. 2014;43(8):2439. DOI: https://doi.org/10.1039/c3cs60351b.

8. Kilinc N, Cakmak O, Kosemen A, Ermek E, Ozturk S, Yerli $Y$, et al. Fabrication of 1D ZnO nanostructures on MEMS cantilever for VOC sensor application. Sensors and Actuators B: Chemical. 2014;202:357-64. DOI: https://doi.org/10.1016/j.snb.2014.05.078.

9. Kasuga T, Hiramatsu M, Hoson A, Sekino T, Niihara K. Formation of Titanium Oxide Nanotube. Langmuir. 1998 $1 ; 14(12): 3160-3$ DOI:

https://doi.org/10.1021/la9713816. 
10. Kasuga T, Hiramatsu M, Hoson A, Sekino T, Niihara K. Titania Nanotubes Prepared by Chemical Processing. Adv Mater. 1999;11(15):1307-11.

11. Anderson C, Bard AJ. An Improved Photocatalyst of TiO2/SiO2 Prepared by a Sol-Gel Synthesis. J Phys Chem. 1995;99(24):9882-5. DOI: https://doi.org/10.1021/j100024a033.

12. Ma S, Li R, Lv C, Xu W, Gou X. Facile synthesis of ZnO nanorod arrays and hierarchical nanostructures for photocatalysis and gas sensor applications. Journal of Hazardous Materials. 2011;192(2):730-40. DOI: https:// doi.org/10.1016/j.jhazmat.2011.05.082.

13. Cao J, Wang A, Yin $H$, Shen $L$, Ren $M$, Han $S$, et al. Selective Synthesis of Potassium Titanate Whiskers Starting from Metatitanic Acid and Potassium Carbonate. Ind Eng Chem Res. 2010 6;49(19):9128-34. DOI: https://doi.org/10.1021/ie101154q.

14. Choy J-H, Han Y-S. A combinative flux evaporationslow cooling route to potassium titanate fibres. Materials Letters. 1998;34(3-6):111-8. DOI: https://doi.org/ 10.1016/S0167-577X(97)00157-2.

15. Makarova NM, Kulapina EG, Tret'yachenko EV, Gorokhovskii AV, Zakharevich AM. Effect of the sorption of polyoxyethylated nonylphenols on the surface structure of potassium polytitanate. Russ J Phys Chem. 2014;88(12):2209-13.

https://doi.org/10.1134/S0036024414120206.

16. Wang $X$, Li Y. Solution-Based Synthetic Strategies for 1-D Nanostructures. Inorg Chem. 2006 1;45(19):752234. DOI: https://doi.org/10.1021/ic051885o.

17. Yuan Z-Y, Zhang X-B, Su B-L. Moderate hydrothermal synthesis of potassium titanate nanowires. Appl Phys A. 2004 Apr;78(7):1063-6. DOI: https://doi.org/10.1007/s00339-003-2165-x.

18. Yu D, Wu J, Zhou L, Xie D, Wu S. The dielectric and mechanical properties of a potassium-titanate-whiskerreinforced PP/PA blend. Composites Science and Technology. 2000 Mar;60(4):499-508. DOI: https://doi.org/10.1016/S0266-3538(99)00149-9.

19. Murakami R, Matsui K. Evaluation of mechanical and wear properties of potassium acid titanate whiskerreinforced copper matrix composites formed by hot isostatic pressing. Wear. $1996 \mathrm{Dec} ; 201(1-2): 193-8$. DOI: https://doi.org/10.1016/S0043-1648(96)07239-0.

20. Wang $B L$, Chen $Q$, Wang $R H$, Peng L-M. Synthesis and characterization of $\mathrm{K}_{2} \mathrm{Ti}_{6} \mathrm{O}_{13}$ nanowires. Chemical Physics Letters. 2003 Jul;376(5-6):726-31. DOI: https://doi.org/10.1016/S0009-2614(03)01068-6.

21. Du GH, Chen Q, Han PD, Yu Y, Peng L-M. Potassium titanate nanowires: Structure, growth, and optical properties. Phys Rev B. 2003 Jan 30;67(3):035323. DOI: https://doi.org/10.1103/PhysRevB.67.035323.

22. Wang $\mathrm{RH}$, Chen $\mathrm{Q}$, Wang $\mathrm{BL}$, Zhang $\mathrm{S}$, Peng L-M. Strain-induced formation of K2Ti6O13 nanowires via ion exchange. Appl Phys Lett. 2005 Mar 28;86(13):133101. DOI: https://doi.org/10.1063/1.1890470.

23. Hanaor DAH, Chironi I, Karatchevtseva I, Triani G, Sorrell CC. Single and mixed phase TiO 2 powders prepared by excess hydrolysis of titanium alkoxide. Advances in Applied Ceramics. 2012 Apr;111(3):149-58. DOI:

https://doi.org/10.1179/1743676111Y.0000000059.

24. Cid-Dresdner $\mathrm{H}$, Buerger $\mathrm{MJ}$. The crystal structure of potassium hexatitanate $\mathrm{K}_{2} \mathrm{Ti}_{6} \mathrm{O}_{13}$. Zeitschrift für Kristallographie - Crystalline Materials [Internet]. 1962 Jan [cited 2021 Jun 14];117(1-6). DOI: https://doi.org/10.1524/zkri.1962.117.16.411.

25. Saleh TA, Gupta VK. Photo-catalyzed degradation of hazardous dye methyl orange by use of a composite catalyst consisting of multi-walled carbon nanotubes and titanium dioxide. Journal of Colloid and Interface Science. 2012 Apr;371(1):101-6. DOI: https://doi.org/10.1016/j.jcis.2011.12.038.

26. Siddiqui MA, Chandel VS, Azam A. Comparative study of potassium hexatitanate (K2Ti6O13) whiskers prepared by sol-gel and solid state reaction routes. Applied Surface Science. 2012 Jul;258(19):7354-8. DOI: https:// doi.org/10.1016/j.apsusc.2012.04.018.

27. Pan $H$, Wang $X$, Xiao S, Yu L, Zhang Z. Preparation and characterization of $\mathrm{TiO}_{2}$ nanoparticles surfacemodified by octadecyltrimethoxysilane. Ind J Eng\&Mat Sci. 2013 Dec;20:561-7. URL: http://nopr.niscair.res.in/ bitstream/123456789/25584/1/IJEMS $\% 2020 \% 286 \% 29 \% 20561-567 . p d f$.

28. Liu G, Wu T, Zhao J, Hidaka $H$, Serpone $N$. Photoassisted Degradation of Dye Pollutants. 8. Irreversible Degradation of Alizarin Red under Visible Light Radiation in Air-Equilibrated Aqueous TiO 2 Dispersions. Environ Sci Technol. 1999 Jun;33(12):20817. DOI: https://doi.org/10.1021/es9807643.

29. Veldurthi NK, Velchuri R, Pola $S$, Prasad G, Muniratnam NR, Vithal M. Synthesis, characterization and silver/copper-nitrogen substitutional effect on visible light driven photocatalytic performance of sodium hexatitanate nanostructures: Silver/copper-nitrogen substituted sodium hexatitanate. J Chem Technol Biotechnol. 2015 Aug;90(8):1507-14.

https://doi.org/10.1002/jctb.4466.

30. Choi J, Cui M, Lee Y, Kim J, Yoon Y, Jang M, et al. Synthesis, characterization and sonocatalytic applications of nano-structured carbon based $\mathrm{TiO}_{2}$ catalysts. Ultrasonics Sonochemistry. 2018 May;43:193-200. DOI: https://doi.org/10.1016/j.ultsonch.2018.01.010. 